\title{
NOTAS SOBRE LA UTILIZACIÓN DEL IMPUESTO DE INCREMENTO DEL VALOR DE LOS TERRENOS EN EL ESTUDIO DE ESPACIOS TURÍSTICOS
}

\author{
J. F. Vera Rebollo
}

\section{RESUMEN}

La búsqueda de nuevas fuentes de información para el estudio de los mecanismos que configuran los espacios de ocio litorales, ha llevado a la utilización de los expedientes e índices-registro del Impuesto sobre Incremento del Valor de los Terrenos. Las variables contenidas en dichos expedientes, aunque difieren en cada municipio, dado que se trata de una imposición municipal autónoma, se concretan en precios indicativos del metro cuadrado de terreno, agentes actuantes en un espacio determinado (adquirentes y transferentes), origen geográfico de los mismos, tipo de inmuebles, lugares afectados por las transmisiones y fecha de la operación (actual y anterior al devengo). La utilidad de esta fuente de trabajo deriva de la posibilidad de correlacionar las distintas variables, cuya información debe ser completada con el estudio de otra importante documentación, los Padrones de solares, y el trabajo sobre el terreno.

\begin{abstract}
The search of new sources of information for the study of mechanims that form holiday resorts along the coast has lead to the use of certain records. Registro del Impuesto sobre Incremento del Valor de los Terrenos. The variables contained in these records, although they defer in each municipality, as they are a municipal independent tax, confine to the following: prices of the square metre of land, agents that operate in a certain area (acquireres and transferents) and their geographical origin, types of properties, places affected by the transmissiones and date of the operation (present day and previous to the substraction). The use of this source of information derives from the possibility of correlating the different variables, yet the information must be completed with the study of other important records, los Padrones de Solares, as well as an intensive fieldwork.
\end{abstract}


Un componente clave en los estudios de ordenación referidos a áreas urbanizadas o sometidas a un proceso creciente de expansión de los asentamientos viene dado por el precio del suelo, de entre cuyas consecuencias principales destaca la especulación. Este tema explica por sí solo los mecanismos de producción del espacio de ocio costero, pues afecta a la dinámica de las transacciones (mercado de compra-venta de inmuebles), formas de planificar el espacio (morfología de planos, ancho de viales), dotaciones comunitarias y zonas verdes, así como a la misma tipología de las construcciones, ya que el grado de especulación justifica el recurso a la edificación en altura y a la aparición de diseños arquitectónicos singulares. Sin embargo, el tema del alza del precio del suelo que motiva el turismo ha sido ostensiblemente marginado, dado que no existen estadísticas de fácil manejo pata su estudio, al tiempo que obliga a una sistematización de posibles fuentes de carácter fiscal, acompañadas de trabajos de campo; esta ausencia se advierte incluso en los estudios de percepción económica (entre los más recientes, vide, FIGUEROLA, M., Teoría Económica del Turismo, Madrid, Alianza Textos, 1985, 434 pp. y GUIBILATO, G., Economie touristique, Denges, Delta \& Spes, 1983, 185 pp.).

Un ejemplo paradigmático de la influencia del precio del suelo en la configuración de un espacio turístico aparece en Benidorm, ciudad en la que el encarecimiento del recurso, al haberse urbanizado en forma de ensanche que prolonga el continuo urbano, justifica la dominante de la edificación en altura y la aparición de zócalos comerciales en los bajos de los edificios, como forma de compensar la inversión necesaria para adquirir el terreno. Tanto es así que la posibilidad, contemplada en las ordenanzas de construcción de las distintas zonas del PGOU, de levantar un determinado número de plantas o de reservar locales comerciales resulta determinante a la hora de programar una actuación en materia de edificación. El precio del suelo es así la causa de la atribución de coeficientes de edificabilidad crecientes en los sectores más avalorados (primera línea de playa) y de la construcción de viviendas cuyos estándares de calidad contribuyen a acentuar el notable proceso de segregación social en el espacio, tan característico de los municipios turísticos.

En las áreas litorales sometidas a la presión turística, el recurso suelo adquiere un valor que nada tiene que ver con su potencial productivo. Así, la nueva percepción económico-funcional del recurso contribuye a asignar un valor de uso, como si de una mercancía se tratase, que depende de nuevos criterios: valoración de las condiciones paisajísticas, proximidad al mar, calidad de 
las playas, accesibilidad, dotaciones y servicios, clasificaciones de suelo dimanantes del planeamiento; en suma, un compendio de factores que atribuyen una renta diferencial (GARCÍA BELLIDO, 1982, BASTIE y DEZERT, 1980). Aunque también hay que insistir en que la obtención de un mayor precio y la dinámica especulativa no es siempre el resultado de la presión de los propietarios del suelo. En bastantes ocasiones ha sido la actuación de los entes públicos la razón de un incremento de precio de los terrenos, tanto si ésta atañe a mejoras en infraestructura y dotaciones, como a las actuaciones desarrolladas a través del planeamiento en cuanto a asignación de usos y calificaciones. No obstante, estas plusvalías no revierten en toda la comunidad, sino en los agentes urbanísticos implicados. Desde una óptica marxista, el valor del suelo implica trabajo incorporado, sin embargo, la singularidad de las áreas turísticas deriva precisamente de que la estrategia de la localización del terreno repercute, sin actividad humana, en el alza del precio, si bien es habitual la referencia al fenómeno como plusvalía en la venta de terrenos.

\section{El Impuesto de Plusvalor (Plus-renta)}

E1 Estatuto Municipal -Decreto Ley de 8-III-1922- confiere a los ayuntamientos la posibilidad, con carácter potestativo, de imponer el Arbitrio sobre Incremento de Valor de los Terrenos en las transmisiones efectuadas que afectan a terrenos edificados y enclaves en suelo apto para edificar. Las Ordenanzas Municipales recogían la aplicación del gravamen de transacciones, partiendo de la consideración de que el incremento de valor de los terrenos se producía sin esfuerzo ni trabajo por parte de sus dueños. De manera que, de acuerdo con la ordenación urbanística existente, se extendía a los terrenos edificados o a las inmediaciones de núcleos urbanos, cuyo valor excedía notoriamente al que les correspondería de acuerdo con su potencialidad agrícola. Pero ya desde el primer momento se plantea la necesidad de establecer un control sobre los otorgantes, por lo que la obligación de pagar el arbitrio se debía notificar a los notarios y al Registro de la Propiedad.

No existe, sin embargo, una verdadera aplicación del gravamen, ni siquiera en los primeros años de desarrollo del fenómeno turístico, cuando las haciendas litorales se convierten en terreno edificable con espectaculares incrementos de precio, sin que por ello se beneficie la economía municipal. Tampoco era de extrañar si se tiene en cuenta que los grupos implicados en la revalorización del espacio costero estaban bien representados en las corporaciones municipales. Así, el mecanismo que supuestamente debía repercutir en una compensación los para ayuntamientos de las cargas derivadas de la consolidación de un espacio turístico, en unas crecientes se torna en sistema de incremento de ganancias para los promotores que, en unas crecientes aspiraciones, llegan a solicitar a las corporaciones la exención en el pago del gravamen cuando se urbanizan unos terrenos, considerando que ya resulta excesivamente gravoso el sistema de actuación, en cuanto a 
ejecución de los Planes, denominado cesión de viales, a lo que se añade que las actuaciones de la iniciativa privada repercutirán en toda la comunidad.

Tras la reforma de la Ley del Suelo y a tenor de la situación creada, junto con las expectativas de aprovechar una fuente de obtención de ingresos por parte de los ayuntamientos, aparece el R.D. 3.250/76 de 30 de diciembre, que en su artículo 98 explicita la obligación, por parte de los registradores, de efectuar el visado municipal antes de formalizar la inscripción en el Registro de la Propiedad, con lo que se garantiza la seguridad de que los ayuntamientos puedan cobrar al otorgante. Además, el mismo R. D. obliga a la elaboración de un registro o padrón de solares en el que debe figurar la superficie, datos del propietario, calificación urbanística, valor asignado y tipo impositivo.

Aparece así, en los municipios que son capitales de provincia o con más de 20.000 habitantes (en el resto con carácter potestativo y de acuerdo con la capacidad de gestión) la Ordenanza Fiscal Reguladora del Impuesto sobre Solares, cuyo hecho impositivo lo constituye la titularidad de terrenos con calificación urbanística de solares (Ley del Suelo) y los terrenos clasificados como urbanos y urbanizable programado, aun cuando estén edificados y no tengan condición de solar. Estos listados son otra fuente importante de trabajo sobre la producción del espacio turístico, de acuerdo con las variables contenidas, de particular interés cuando se pretende conocer el cambio de titularidad de los terrenos y los grupos implicados en la afectación hacia el uso residencial. No menos interés tiene la posibilidad de conocer la estructura de la propiedad del suelo edificable, pues en tales áreas se desarrollan las actuaciones urbanísticas, con los obvios condicionantes derivados de las formas de concentración o dispersión de los solares, que tienen su reflejo en el mismo planeamiento.

\section{Confección y utilidad de los expedientes del impuesto}

La aplicación del impuesto impone la necesidad de realizar una zonificación del territorio afectado, acorde con las tendencias observadas en el proceso de ocupación del suelo y en la renta diferencial; pero que también trata de ajustarse al aprovechamiento urbanístico que delimita el planeamiento: casco antiguo, ensanche (diferencia primera línea), planes parciales consolidados, enclaves, convenios urbanísticos e incluso a escala de manzanas y calles. A tenor de esta zonificación se elabora un cuadro de valores, con los precios unitarios en ptas. por metro cuadrado, válido inicialmente para un trienio pero que en la actualidad se suele revisar cada dos años (el período mínimo de vigencia es de un año). Tales valores tienden a acercarse al precio real del terreno, aunque rara vez lo alcanzan. En este sentido hay que señalar la intención de los municipios turísticos de obtener unos ingresos en concepto del plusvalor, en tanto que imposición municipal autónoma, que lleva a ajustar los precios unitarios de los cuadros de valores a la realidad del mercado inmobiliario. 
Con los Cuadros de Valores se calcula la base imponible en cada transmisión, entendida aquélla como la diferencia entre valor final (momento del devengo) y valor inicial (última transmisión anterior al devengo); por último, las tarifas resultan de dividir el tanto por ciento que represente el incremento respecto del valor inicial por el número de años en que se ha producido. Por tanto, el plazo de años transcurrido desde la última transmisión es un parámetro fundamental en la obtención de rentas del suelo.

Se puede señalar que a medida que el número de años de inmovilización aumenta, menor es el precio a pagar, por tanto, se trata de gravar en mayor medida las transacciones realizadas con un corto período de tiempo de retención, indicativo de que el grado de especulación resulta más elevado. Naturalmente este planteamiento puede ser rebatido desde el momento en que la retención de un terreno durante un largo intervalo de tiempo conduce a sustanciales incrementos de precio, sin haberse realizado inversión alguna; basta señalar al respecto la revalorización que experimentan los terrenos de antiguas fincas de secano ubicadas en la vecindad del mar y que se han mantenido como Suelo Rústico (Suelo no Urbanizable) hasta fechas recientes, es decir, fuera del objeto del impuesto.

Junto con los cuadros de valores, los datos a manejar aparecen en los expedientes de liquidación, correspondientes a las distintas transacciones y que se suelen agrupar por años. Por ello debe matizarse en principio la diferencia que existe si se manejan los propios expedientes o si por el contrario sólo se dispone de índices-registro, con una serie de variables anotadas por cada transmisión efectuada. En cualquier caso, las variables que resultan de utilidad desde nuestra óptica se concretan en:

1. Precios indicativos y aproximados del valor del metro cuadrado de terreno, que deberán contrastarse con los obtenidos a partir del trabajo de campo.

2. Agentes actuantes en un municipio determinado, con la obvia diferenciación entre adquirentes y transferentes. Se puede conocer así el tipo de compradores (empresas, particulares, promotores) y el de vendedores, siguiendo la trayectoria a la desmembración de grandes predios, o en su caso, ventas hechas por particulares, agricultores, etc.

3. En relación directa con la variable anterior figura el origen geográfico de estos agentes implicados en las transacciones, de forma tal que es posible conocer la procedencia de las empresas y promotores actuantes, así como de los propietarios iniciales del suelo (locales o foráneos) y de los especuladores que suelen ir apareciendo en este tipo de sistemas. El número de operaciones da idea de la envergadura y volumen de los negocios efectuados por cada colectivo. Es más, se puede llegar a concretar unas relaciones de dependencia entre municipios turísticos litorales y ciudades interiores; por ejemplo, en Benidorm existe un importante grupo de promotores -constructores de origen madrileño, mientras en 
Torrevieja la vinculación se produce respecto a los núcleos de la comarca rural circundante y de la propia capital murciana.

4. La distinción de tipos de inmuebles resulta fundamental para atender el sistema y tipo de venta predominante en cada espacio turístico y en cada período; tras una fase inicial en la que predominan las transacciones que atañen a la venta del suelo, comienza una segunda caracterizada por la compra-venta de apartamentos y chalés, mientras que la fase actual suele venir singularizada, en el caso alicantino, por la venta de bungalows. Naturalmente se puede concretar más por años y actuaciones predominantes y establecer una relación con las condiciones de la demanda.

5. Los lugares afectados en el término municipal conviene agruparlos con arreglo a una distinción de sectores con suficiente arraigo y homogeneidad en cuanto a las tendencias en el mercado inmobiliario. En el tejido urbano los sectores delimitados podrán coincidir con una trama urbanística concreta: núcleo antiguo (casco antiguo), ensanche, mientras que el diseminado y urbanizaciones será imprescindible el recurso a la inspección sobre el terreno y a la encuesta para llevar a cabo la delimitación de áreas.

Una vez que se establece esta delimitación, se puede conocer la evolución en cada sector, etapas de mayor intensidad de las transmisiones y tipos de actuaciones predominantes.

6. Una variable de primordial interés en este tipo de trabajos es la fecha de las operaciones, ya que figura la de la última transmisión del inmueble en cuestión y la correspondiente a la operación objeto del expediente que se maneja; es decir, se conoce el intervalo de tiempo transcurrido entre la adquisición y posterior venta del inmueble. La disponibilidad de tales datos permite conocer la intensidad de las operaciones en cada año, pero también facilitada el que denominamos período de retención, indicador de las condiciones del mercado y del grado de especulación existente. Se ha podido comprobar que en espacios afectados intensamente por la urbanización turística el período de retención de los inmuebles tiende a reducirse, mientras que es en la venta de terrenos donde se registran los mayores intervalos de retención, sobre todo cuando se trata de fincas rústicas, cuyo desmembramiento y consiguiente parcelación con fines edificables constituye un fenómeno novedoso en los años 1960.

A tenor de lo anteriormente expuesto resulta obvio que el verdadero sentido de este tipo de análisis surge al considerar la interrelación de las seis variables comentadas. Así, el trabajo resulta fructífero cuando a la consideración única de precios, origen geográfico o cualquier otro componente se plantea como alternativa la interrelación de agentes, origen geográfico y clase de inmuebles, que denota tipos muy concretos de demanda o, en su caso, de propietarios y constructores. Particular interés reviste en el mismo sentido la relación de las variables período de retención y tipo de inmueble, que permite caracterizar las etapas de configuración del municipio turístico y el grado de especulación alcanzado. En 
resumidas cuentas, se hace aconsejable tanto desde el punto de vista del rendimiento que puede obtenerse como de la facilidad de la tarea, el tratamiento informatizado de los datos mediante un programa que permita la correlación de las distintas variables, e incluso obtener material gráfico de dicha relación.

No obstante, esta fuente de trabajo presenta limitaciones que derivan del carácter fiscal de la misma y de su aplicación a escala de municipios, con la consiguiente falta de homogeneidad en tratamiento, aplicación e incluso formato de los expedientes y registros. Del análisis de 20 municipios costeros se desprende una serie de cuestiones que deberá ser considerada para el tratamiento de la información:

a) De las seis variables referidas puede ocurrir, fundamentalmente en ayuntamientos pequeños y con escasa capacidad de gestión, que falte alguna en los índices registro, mientras que los expedientes de liquidación no se suelen archivar. Con ello se establecen restricciones a un análisis de correlación de variables.

b) Cuando el estudio abarca varios municipios es frecuente que los índices-registro no sean similares, es decir, no aparecen todas las variables en el conjunto.

c) En determinados casos, puede faltar la fecha de la última transmisión, con lo que se ve imposibilitada la realización de un estudio de períodos de retención. Otra cuestión importante atañe a la fecha del expediente, ya que no suele ser la fecha real de la operación, sino la de la notificación al ayuntamiento; de ahí que la diferencia pueda ser en ocasiones extrema, sobre todo en períodos con una intensa actividad de compra-venta, situación que motiva a los especuladores que adquieren un inmueble para revenderlo a no realizar la correspondiente inscripción registral.

d) Otro inconveniente que puede aparecer en este tipo de trabajos deriva de la falta de precisión conceptual, que lleva a confundir o asimilar distintos tipos de inmuebles en los expedientes. Así, es bastante frecuente la imprecisión de los términos piso, edificio, vivienda y apartamento; hasta tal punto que en algunos municipios las denominaciones piso y apartamento se utilizan indistintamente, pero también puede ocurrir que vivienda aluda a apartamento, lo mismo que a chalé aislado. En este sentido, sería extraordinariamente apropiada la disponibilidad de un formato único de expediente y de índice-registro para todos los ayuntamientos, con las mismas variables y conociendo el significado de éstas. Una cuestión que no debe pasarse por alto es que en los mayores ayuntamientos los listados han sido mecanizados, incluyendo las liquidaciones, lo que puede facilitar la tarea, siempre y cuando el carácter fiscal de los datos nos los haga inasequibles para el investigador.

Como conclusión, se está ante una fuente de trabajo de gran utilidad a la hora de interpretar la configuración y producción del espacio turístico, si bien para obviarlas susomentadas limitaciones es aconsejable completar la tarea con 
recorridos sobre el terreno, que permiten comprobar el tipo de construcción predominante y la denominación más usual que recibe cada uno de ellos en la zona, así como el peso y origen de las corrientes de afluencia, grupos de vendedores, etc. Y, obviamente, el trabajo in situ permitirá recabar información relativa a precios reales del suelo, que podrán compararse con los asignados en los Cuadros de Valores y con la zonificación realizada. El manejo de esta fuente de obtención de datos alcanza mayor rendimiento y validez si se acompaña del estudio de los Padrones de Solares y, sobre todo, si se relaciona con el proceso de ocupación del suelo, a través del estudio sistemático de las licencias de edificación. Así es posible establecer correlaciones en cada período entre disponibilidad de suelo edificable, precios, ritmo de construcción de nuevas viviendas (distinguiendo tipos y precio del metro cuadrado construido) y agentes actuantes, tanto en la venta y adquisición de terrenos como en la promoción de las nuevas edificaciones. Son, en suma, componentes fundamentales para captar los mecanismos que dinamizan los espacios de ocio litorales.

Alicante, marzo de 1987.

\section{BIBLIOGRAFÍA FUNDAMENTAL}

BASTIE, J. Y DEZERT, B., L 'espace urbain, París, Masson, 1980, pp. 88-92.

FERNÁNDEZ, T. R., Manual de Derecho Urbanístico, Madrid, Publicaciones Abellá, 1985, 262 pp.

GARCÍA BELLIDO, J., «La especulación del suelo, la propiedad del suelo y la gestión urbanística», Ciudad y territorio, $\mathrm{n}^{\circ}$. 3, 1982, pp. 45-73.

LIPIETZ, A., Le tribut foncier urbain, París, F. Maspero, 1974.

VERA REBOLLO, J. F., Turismo y urbanización en el litoral alicantino, Instituto Universitario de Geografía, Universidad de Alicante y Colegio Oficial de Arquitectos (en prensa).

En cuanto a legislación, las normas del Impuesto sobre Solares están contenidas en los artículos 231 a 233 y 349 del T. R. de Régimen Local, mientras que las del Incremento de Valor de los Terrenos aparecen en los artículos 231 y 350 a 361 . 